\title{
LA NOVELA EN LA NUEVA ESPAÑA
}

\author{
P O R \\ JOSE ROJAS GARCIDUEÑA
}

$\bar{F}^{\mathrm{N}}$ términos generales cabe afirmar que ninguna expresión cultural C de la Nueva España puede ser debidamente aquilatada si no se examinan, previamente, las manifestaciones culturales análogas de España. Por lo demás, esto ocurre, en esferas de mayor o menor amplitud, en todas las cosas y en escala más o menos vasta según el asunto y el momento histórico de que se trate; en otras palabras: que los fenómenos culturales no son particulares ni autónomos ni autóctonos y siempre tienen vinculaciones espaciales y temporales con otros fenómenos similares en un radio que también varía en el espacio y en el tiempo; pero, también, en el caso de la cultura de Nueva España es más concreto y directo el antecedente considerable, ya que deliberadamente se pretendía, casi siempre, copiar o imitar o continuar los motivos metropolitanos, aunque involuntariamente $e$ inconscientementc en las realizaciones novohispanas se fueran introduciendo variantes $o$ modalidades que son ahora, para nosotros, algunas de las características más valiosas, por cuanto son expresiones de la diferenciación que ha ido definiendo nuestra propia, separada y auténtica personalidad social y nacional, dentro del gran complejo cultural al que denominamos cultura europea $u$ occidental.

Por todo eso, dejando aparte las consideraciones de largo alcance y reduciéndolas al estrecho campo del propósito del presente estudio, que es el de tratar acerca de la novela en la Nueva España, es indudable que el obligado principio debe estar en el examen de ese género 
literario en España, desde los años inmediatamente precedentes a la llegada de los españoles a México hasta que la corriente cultural española conformó la de la Nueva España, digamos (sin rigor y sólo como una apreciación básica muy general), que tal examen debe referirse a los primeros cien años de la dominación española, o sea que conviene mirar, en rapidísima ojeada, qué se produjo, dentro del género novelesco, en la España del siglo Xvi.

En ese lapso, allá, no solamente se cultivó la novela, sino que el género proliferó en varias especies.

Desde luego, y con raices que se adentran en la Edad Media, encontramos la novela caballeresca o de caballerías, con el Amadis de Gaula, de origen y cronología nada precisos pero ya difundido y popular en el reinado de los Reyes Católicos, tránsito evidente de dos épocas. El quinto libro de Amadis y las Sergas de Esplandián aparecen a los comienzos del siglo xvi y les siguen, durante la primera mitad de tal centuria, la serie de los Palmerines, y luego toda la ristra de novelones que secaron el seso a Don Quijote hasta que éste mismo, con su magnífica insania y sus descomunales hazañas, puso de hecho punto final y cerró, esta vez sí con llave de oro, el largo ciclo de aquellas novelas de caballerías de tan largo y rico florecimiento.

De origen renacentista son la novela sentimental (como la Cárcel de amor y otras posteriores) y la novela pastoril, importada de Italia y cultivada en España, con lustre, por Jorge de Montemayor y Gil Polo, con sus respectivas Dianas, más otros autores de variada importancia pero, sobre todos, Cervantes, que publicó la primera parte de su Galatea en 1585 y aún esperaba proseguirla treinta años después, ya en trance de muerte.

Novela bizantina suele llamarse a la de aventuras, de la que también se encuentran diversas muestras españolas en el siglo xvi y aun en el xvir, como por ejemplo la última obra de Cervantes: Los trabajos de Persiles y Sigismunda.

En la misma época una variedad novelística surge, la picaresca, encabezada por el Lazarillo y luego fructificará, en pleno barroquismo con obras de Alemán, Quevedo, Esquivel y otros.

Aun podrían citarse las abundantes novelas cortas, al estilo de las italianas del Bandello, Boccaccio y otros renacentistas. Quienquiera puede aumentar la lista con sólo revisar una Historia de la Literatura Española, pero creo que no tiene objeto hacerlo aquí y que bastan las alusiones antedichas para recordar que la novelística española era 
ya considerable antes de la llegada de los españoles a México (es decir en los años precedentes al reinado de Carlos V) y que mucho más se enriqueció en los cien años que siguieron a la caída de Tenochtitlan.

No pudo, pues, haber mejor antecedente, desde el punto de vista exclusivamente literario, para una posible producción novelística en los dominios españoles; si, muy al contrario, esa producción fue casi nula, ello debe explicarse por causas extraliterarias; ya se ha intentado hacerlo, acudiendo a las prohibiciones legales y administrativas, pero acaso no hayan sido esos los motivos decisivos ni menos aún los únicos y yo me atrevo a sugerir que tal vez una investigación cuidadosa en el terreno de la economia: costos de impresión, costos de papel, mercado controlado por libreros importadores, etc., podria arrojar mayores luces; por desgracia, la historia económica de la Nueva España o el conocimiento de la economía de aquella etapa de nuestra historia es una terra incognita que ningún investigador ha explorado seriamente. Quede eso así apuntado antes de que nos lleve a más digresiones de nuestro asunto.

Que no se leían novelas en la Nueva España, porque su introducción a este reino estaba severamente prohibida, fue cosa dicha y repetida durante años: porque algún erudito encontró las reales cédulas de prohibición y no buscó más y dio por hecho que aquellas leyes se observaron y cumplieron al pie de la letra, luego otros escritores, de cuando en cuando, volvian a repetir lo mismo y todo llegó a tenerse por verdad sin discusión posible. Cuando alguien encontraba la clara huella de alguna novela española en este suelo, en tiempos del virreinato, tenlase el hecho por cosa de excepción, y yo recuerdo haber lefdo más de una vez, probablemente en relatos, cuentos y croniquillas al modo "colonialista", que privó en el gusto de allá por los años "veintes" de este siglo, que el héroe del cuento daba tres vueltas a la llave de su aposento, cerraba las ventanas y a la luz de un candil de dos velones sacaba del fondo del herrado cofre un libro, que podía ser El Picaro Guzmán de Alfarache o el propio Ingenioso Hidalgo Don Quijote de la Mancha, y acabado el rato de lectura volvía a guardar el libro con tamaño sigilo, por miedo a ser descubierto por los corchetes del Santo Oficio, cuyos pasos crela oir en todo momento el atemorizado lector que cometía el delito de poseer aquel volumen. 
Las prohibiciones para que acá viniesen libros de ficción efectivamente existieron: la real cédula de abril de 1531 y otras semejantes, a lo largo del siglo XVI, pero igualmente cierto es que los libros de ficción llegaban a Veracruz y se vendían en México. Dar aquí las pruebas correspondientes sería largo, aunque muy interesante, citando pormenorizadamente algunas de las listas de remesas, documentadas y aprobadas por la Casa de Contratación, de las que contienen abundantes títulos de novelas españolas o traducidas al español, traídas por las flotas y vendidas por libreros que de ello tenían público negocio en la capital u otras ciudades del reino de Nueva España. No es posible copiar aquí tales listas pero sí cabe, y lo hago con el mayor encarecimiento, recomendar a quien se interese por este asunto que lea el muy buen estudio, a la par que ameno, de Irving A. Leonard, titulado originalmente Books of the Brave, traducido al español por Los libros del conquistador, cuya edición mexicana (Fondo de Cultura Económica, México, 1953) debe preferirse por tener los apéndices que la edición norteamericana no contiene y que son, precisamente, algunas de aquellas listas de libros remitidos de España a los que líneas arriba he aludido. ${ }^{1}$

Pero si las prohibiciones para traer libros de ficción a las Indias Occidentales no se cumplían -aunque siempre quedaron teóricamente vigentes, ya que no fueron legalmente derogadas-, otra cosa muy distinta sería la posibilidad de publicar libros semejantes en las imprentas de México. Cabe suponer que si algún autor de novelas tuvo el natural deseo de ver su creación en letras de molde, desistiría de su intención al considerar o averiguar que los necesarios permisos de las autoridades civiles y eclesiásticas tropezarfan con el duro escollo de las leyes, y acaso en ciertas épocas de gobernantes en extremo escrupulosos o timoratos o de estrechísimo criterio - que así lo hubo y no fueron pocos-, el autor que hiciese gestiones para editar libros profanos e imaginativos podría

1 Las listas publicadas por I. A. Leonard, relativas a libros remitidos a Nueva España, corresponden al siglo Xvi. Investigaciones semejantes han sido continuadas, afortunadamente, aquí en México por diversos historiadores; al respecto cabe citar, especialmente, las siguientes: Guillermo S. Fernández DE Recas, "Libros y libreros de mediados del siglo xvir en México", en Boletin de la Biblioteca Nacional (No 2, t. IX abril-junio de 1958; No 2, t. x, abril-junio de 1959; Nos. 1 y 2, t. xII, enerojulio de 1961 y Nos. 3 y 4, t. xII, julio-diciembre de 1961), Universidad Nacional Autónoma de México. En cuanto al siglo xviri, en diversos estudios hay referencias a los libros que eran lefdos (permitidos o prohibidos) en esa época; uno de tales estudios es: M. L. Pérez Marchand, Dos etapas ideoldgicas del siglo XVIII en México, Ed. El Colegio de México, 1945. 
verse en la molesta situación de ser considerado como sospechoso de intentar una violación al orden legal. En tales condiciones si es explicable que los escritores no gastaran sus esfuerzos en esas tareas inútiles o peligrosas y que, en los contados casos en que llegaron a escribir novelas, éstas quedaran manuscritas, conocidas solamente de corto número de amigos lectores, por lo cual algunos títulos de novelas han llegado hasta nosotros en las referencias de bibliógrafos y eruditos, pero no en ejemplares impresos.

Claro es que quedaba un camino diferente: editar esas obras en España, donde los permisos se daban regularmente por trámite acostumbrado; asf lo hizo Bernardo de Balbuena, pero fue el suyo caso especial y su ejemplo era inútil para casi todos que no podían vivir más o menos tiempo en la metrópoli, cultivar alli amistades, hacer arreglos personales, etc., para la publicación de sus obras.

Así, pues, mirando no hacia las prohibiciones de importación sino a las dificultades y trabas para las impresiones en el propio suelo, es como debemos interpretar la tradicional aseveración de que los impedimentos legales - latu sensu - frenaron, hasta hacerla casi inexistente, la producción de novelas en la Nueva España. Sin embargo, como antes dije, creo que la cuestión fue más compleja y repito que la investigación debe encaminarse por rumbos como los de la economia, disciplina tan ignorada de los historiadores de la cultura (historias del arte, de la literatura, etc.) que, victimas a veces de lamentables prejuicios, han visto los estudios económicos con desdén y la consecuencia es haber tratado de construir explicaciones históricas sin base ( $y$ a veces sin pies ni cabeza) o haber tergiversado las consecuencias de ciertos hechos o no haber podido encontrar las causas de otros, como acaso ocurre en este pequeño problema de la novelística novohispana.

Dejemos, pues, para otros estudios, la resolución del porqué de la escasez de novelas en la América hispana y vengamos, por ahora, a repasar los casos -que aunque pocos, algunos hubo-, en que la novela se cultivó en la Nueva España.

El primero de los ejemplos de la novelistica novohispana es, al mismo tiempo, el más incuestionable pero el más frecuentemente ignorado u olvidado. De uno y otro de tales hechos haré, más adelante, algunas observaciones. 
En 1608 apareció en Madrid la pequeña obra de Bernardo de Balbuena: Siglo de Oro en las Selvas de Erifile. Es una novela pastoril, y desde su portada nos avisa que ha sido hecha en "agradable y rigurosa imitación del estilo pastoril de Teócrito, Virgilio y Sannazaro..." y es cierto que sigue, muy de cerca, la traza y el aliento de la Arcadia del italiano. Hoy, sin duda, podría parecer a ciertos lectores algo así como "poca novela y mucho verso" (hipótesis remota, pues nadie la lee ni la conoce por lo distante del gusto moderno y la extrema rareza del libro en sus dos ediciones), pero tal apreciación no andaria muy errada: una débil construcción, un delgado hilo de acción casi sin conflicto, unos personajes que, como he dicho en otra ocasión, más que seres humanos "son figuras de un tapiz y de una alegoría, como si vueltas móviles y animadas las figuras de La Primavera de Botticcelli, se pusieren a decir y a cantar amorosos coloquios y suaves églogas pastoriles". Pero igual ocurre en los otros ejemplos del género: la Diana Enamorada de Gil Polo, la Menina e moça, de Bernaldino de Ribeiro, la misma Galatea cervantina; ese ambiente idealizado y artificioso, esos pastores transidos de amor, esa suave y espiritual vida proyectada exclusivamente a lo poético (en el doble rigor del término, como producto de creación y como emoción de belleza), todo eso es precisamente lo característico de la novela pastoril y serfa negar el género si, por esas calidades tan ajenas a la novela actual, fuésemos a desconocer como novela el Siglo de Oro de Balbuena.

Esa obra fue escrita en Nueva España, más concretamente comenzada en México hacia 1585-90 y retocada más tarde, en Guadalajara u otro lugar de Nueva Galicia, acaso en los primeros años del nuevo siglo; es pues, obra de juventud de Balbuena quien nos da en ella ciertas alusiones autobiográficas, ${ }^{2}$ con referencias fugaces a la laguna de México y otros sitios, todo encubierto poéticamente.

Por eso me parece incuestionable que está fuera de duda que el Siglo de Oro, de Balbuena, es novela y es de Nueva España. ¿Por qué, entonces, se la olvida o se la ignora al citar los ejemplos de la novela de nuestro país durante el virreinato?

La explicación, que no justificación, creo que puede deberse a estos tres factores que aquí solamente señalo:

2 José Rojas Garcidueñas: Bernardo de Balbuena. La vida y la obra. Instituto de Investigaciones Estéticas, Imprenta Universitaria, México, 1958. 
a) Porque Balbuena es poco conocido; los que lo recuerdan se fijan en que nació en Valdepeñas, lo tienen por español indudable y no lo mencionan al hablar de las letras de Nueva España, pero es ignorancia, porque Balbuena llegó aquí en plena juventud, estudió en Guadalajara de Nueva Galicia y en México, vivió en este suelo hasta sus cuarenta años y sólo después fué a España y luego a las Antillas donde pasó el último tercio de su vida. Sin negar que fuese español, de la vieja España, lo fue más aún de la Nueva y así debe de ser considerado.

b) Por haber sido publicado en Madrid el Siglo de Oro también se tiende a olvidarlo cuando se habla de libros mexicanos, pero consta que ya estaba escrito aquí y fue enviado allá desde 1602, antes de que Balbuena fuese a España $y$, por lo tanto, el lugar de impresión nada importa, pues si en vez de impreso en Madrid lo hubiera sido en París no por eso dirfamos que ese libro pertenece a las letras de Francia.

c) Porque suele repetirse que el Siglo de Oro es una colección de églogas, lo cual es en gran parte cierto, pero ya dije que igual ocurre con toda la novela pastoril.

En resumen, el Siglo de Oro en las Selvas de Erifile es, indiscutiblemente, un ejemplo, el primero en tiempo y yo creo que también en calidad, de la novela pastoril de Nueva España.

El segundo es otra novela de la misma especie: Los Sirgueros de la Virgen, de Francisco Bramón, impresa en México en 1620. Libro rarísimo en la edición princeps, la Universidad lo hizo figurar en su Biblioteca del Estudiante Universitario pero, desgraciadamente, no lo reprodujo integro, seguramente para ajustarlo a los requisitos de la edición; a pesar de eso cualquier lector puede ver que se trata de una novela pastoril sui generis pues el tema amoroso, fundamental en la novela pastoril, aquí se traspone a un plano religioso y los versos y canciones que normalmente estarfan dirigidos a las gentiles pastoras de doradas trenzas y tiernas miradas, en esta novela del Padre Bramón las endechas van dirigidas a la Virgen Marja, que desplaza todo amor humano de los rendidos corazones de los pastores; ya se comprenderá que, si de suyo propio la novela pastoril padece debilidad de acción y de conflicto y exceso de artificiosidad e idealización, todo eso no puede sino exacerbarse con este tour de force; además, la novela pastoril es sólo una parte de la obra de Bramón, pues los pastores enamorados de la Virgen preparan y hacen fiestas en honor de María y esas fiestas, como en la realidad contemporánea del autor, culminan en la representación de un Auto en loor de 
la Inmaculada Concepción, que es en sí mejor que la parte de novela bucólica que lo precede. Así, pues, muy débil trazo en la novelística virreinal es la obra de Bramón, escrita en pleno barroquismo pero que corresponde literariamente a una etapa renacentista anterior, con su matiz un poco desconcertante en el título, ese arcaico sirgueros por jilgueros que, además, debe tomarse en sentido metafórico en lugar de cantores. De cualquier modo, y con todas sus debilidades, Los Sirgueros de la Virgen sin original pecado, es la segunda de las novelas escritas en la Nueva España.

No cabe duda, conforme queda probado líneas arriba, que la primera novela novohispana fue El Siglo de Oro en las Selvas de Erifile y la segunda, ésta de Bramón, Los sirgueros de la Virgen; ${ }^{3}$ pero todos cometemos errores y hasta un escritor tan cuidadoso y puntual como lo era don Alfonso Reyes sufre alguna vez un desliz, que si aquí quiero rectificar es precisamente para que se repare en él y no perdure por el puro aval de quien lo puso y hubiera sido el primero en corregirlo, de haberlo advertido. Dice Reyes: "La más temprana que poseemos (y ya es forzar la mano el llamarle novela, aunque sea por respeto a los manes de don Marcelino) es obra del Bachiller Francisco Bramón..." 4 Pero Reyes olvida que, algunas páginas antes, él mismo habia hablado de "El siglo de oro en las selvas de Erifile, novela pastoril en metro..."

Con fecha un poco posterior a la antedicha, menciona otra novela el hoy tan olvidado don Francisco Pimentel, que dice: "Juan Piña Iz-

3 Siglo de Oro en las Selvas de Erifile del Doctor Bernardo de Balbuena, en que se describe una agradable y rigurosa imitación del estilo pastoril de Técrito, Virgilio y Sanazaro, dirigido al Excelentisimo Don Pedro Fernández de Castro Conde de Lemos y de Andrade Marques de Sarria y Presidente del Real Consejo de Indias. Año 1608. Con privilegio en Madrid, por Alonso Martin, a costa de Alonso Perez, mercader de libros.

Los Sirgueros de la Virgen sin Original Pecado. Dirigido al Illvstrissimo Señor Don Fr. Balthasar de Cobarruvias del Consejo de su Magestad, Obispo de Mechoacan. Por el Bachiller Francisco Bramón, Consiliario de la Real Vniversidad de México, con licencia, Año 1620. La 24 edición (incompleta, como queda dicho arriba): Francisco Bramón, Los Sirgueros de la Virgen. Prólogo y selección de Agustin Yánez. Biblioteca del Estudiante Universitario, vol. 45. Ediciones de la UNAM, México, 1944.

4 Alfonso Reyes: Letras de la Nueva España. Colec. Tierra Firme, vol. 40. Fondo de Cultura Económica, México, 1948, p. 89.

5 Ibidem, p. 77. 
quierdo, natural de Buendía, en Castilla, ejerció en Madrid el oficio de notario de la Inquisición y habiendo pasado a Nueva España se avecindó en Puebla, donde fue Notario Apostólico y Escribano Real. Dio a luz varias obras en prosa, entre ellas sus Novelas Morales (Madrid, 1624)." 6 ¿Por qué incluirfa Pimentel a ese escritor entre los "Novelistas y oradores mexicanos"?; pues uno es el caso -como el de Balbuena- del escritor nacido en España, pero formado intelectualmente (y me siento impulsado a añadir también sentimental o emocionalmente) en México, y otro muy distinto es el caso del escritor que vino aquí ya con su personalidad y su cultura conformadas allá y tal vez hasta con obra hecha y lanzada al mundo, cansado y exhausto, sólo en busca de un mejor acomodo y en vísperas de morir, cual ocurrió con el insigne Mateo Alemán, cuyas pequeñas obras escritas aquí (la Ortografia y los Sucesos de fray Garcia Guerra) de ningún modo puede alegarse que correspondan a la literatura propiamente mexicana de la época virreinal. De un libro cuyo autor no era de esta tierra ni se educó aqui, difícilmente podría justificarse el hacerlo figurar en la novelística mexicana del virreinato.

Pero otros casos hubo, como arriba quedó apuntado: los de novelas indudablemente concebidas y escritas aquí pero nunca publicadas. Una de esas novelas inéditas, que hoy parecen perdidas definitivamente, es La caida de Fernando, escrita por el Pbro. y Lic. don Antonio de Ochoa, hacia el año de 1662. Los bibliófilos y eruditos recordarán que de la obra y del autor hace mención Beristáin y Souza en su Biblioteca Hispano Americana Septentrional, pero durante casi siglo y medio nadie volvió a dar la menor noticia de aquella novela, hasta que otro bibliógrafo, el Dr. Ernest R. Moore, gran investigador de nuestras letras, encontró otra referencia directa que publicó en una breve pero muy interesante nota. ${ }^{\top}$ Por la dificultad que pueden tener algunos lectores, interesados en este asunto, en ver la nota de Moore (ya que de la Revista de Literatura Mexicana sólo aparecieron dos números, hace más de veinte años, por lo que no es fácil su consulta), y por el deseo de concentrar aquí las noticias que a la fecha se tienen acerca de la novelística a que se refiere este artfculo, me permito citar todo un párrafo de Moore y luego otro del manuscrito al que él se refiere.

6 Francisco Pimentel: "Novelistas y Oradores Mexicanos", en Obras Completas, t. v. Tip. Económica, México, 1904, p. 276.

7 ERnest R. MOORE: "La primera novela histórica mexicana", en Revista de Literatura Mexicana, Año I, No 2, México, octubre-diciembre de 1940, pp. 370-378. 
Después de citar a Beristáin y algún otro precedente y de aludir al posterior silencio que cayó sobre la novela mencionada (lo que se explica porque nadie volvió a verla jamás), habla Moore de un documento del siglo xvill que él encontró:

"Este documento... es obra de algún historiógrafo mexicano, que tuvo la novela a la vista en 1757, casi cien años después de cuando la dejó escrita el padre Ochoa. Según parece, el autor del documento mencionado la leyó con el propósito de sacar algunos apuntes relativos a la fundación de la ciudad de Puebla... La extensión del manuscrito hace creer que se trata de una novela, más bien que de un documento histórico. ${ }^{8} \mathrm{Y}$ aunque la obra tiene pretensiones históricas no carece de interés novelístico, ya que el historiógrafo que sacó de ella sus apuntes la llama novela. Si fuese nada más que un documento histórico, es seguro que así lo habría dicho, para dar mayor valor a los hechos que copió. Es de presumir, por lo tanto, que la obra está compuesta con cierta trama o en episodios fantásticos que impidieron al historiógrafo llamarla simplemente historia, en vez de novela. $Y$ en este punto sigue lo que dijeron Bermúdez de Castro antes y Beristáin después; debemos, pues, tomar esta conformidad de opiniones como una prueba de lo que dejó escrito Antonio de Ochoa fue una obra novelistica..."

El primer párrafo del documento en cuestión, encontrado y publicado por Moore, que no consta más que de cuatro cuartillas, de clarísima letra del siglo xviII, dice así:

"Apuntes sacados de la Novela Manuscrita, que por los años de 1662 escrivio el Lizdo Antonio de Ochoa Presbitero de la Ciudad de la Puebla de los Angeles en que haze una descripcion de esta Ciudad. La huve â las manos en dha Ciudad de la Puebla por el mes de Agosto de 1757. y de ella he sacado los apuntes sigtes. La copia que tuve de donde los saque eran vn quaderno en quarto con 142 foxs, sin repartimto de Capitulos, ni numerazn de Parrafos: Casi a la mitad de la novela comienza la descripción de la Puebla y en el

8 Muy curiosa es la proposición del erudito doctor Moore: tal parece como si, para él, los documentos históricos debieran constar de tantos más cuantos pliegos y, si hubiera foja de más, debieran ya no ser históricos sino llamarse o calificarse de novelas. 
primer Parrafo dise que en un legajo de papeles mui antiguos hallo vn apunte (que cree fuese de alguno de los primeros fundadores) en que constaba el día de su fundazion y los nombres de sus primeros fundadores, el que copio â la letra, y es como se sigue...".

Como se ve, el anónimo redactor del documento de 1757 llama dos veces "novela" al manuscrito del padre Ochoa; Ernest R. Moore también la llama novela, añadiendo motivos que no lo son: como el número de páginas y el que si el lector del siglo xvill lo hubiera juzgado historia, lo habría dicho. Pero también sigue en su mismo lugar (de crédito o de duda, como se quiera mientras no haya más pruebas) la ficha consignada por un lector tan afanoso como el erudito Beristáin y Souza, que dice:

“Ochoa (D. Antonio) natural de la Puebla de los Angeles; mayordomo allí del monasterio de S. Gerónimo, y del Colegio de Jesús a él anexo. Fue hombre instruido en letras humanas y escribió la Historia de aquel Colegio, que más bien parece una Novela, intitulada: La Caida de Fernando. MS de que hace mención Bermúdez. de Castro en su Catálogo Núm. 147." 10

Claramente dice Beristáin, que Ochoa escribió una Historia del Colegio de Jesús "que más bien parece una Novela..." o sea que, a su juicio, el tal manuscrito era fundamentalmente una historia (es decir una relación o compilación de datos y sucesos reales) pero que estaría dicho escrito redactado, tal vez, con mezcla de sucesos ficticios o acaso envuelto en trama de episodios imaginados, lo que lo asemejaba a una novela. ¿Serfa un caso, el primero en letras mexicanas y antes que con el romanticismo surgiera ese subgénero literario, de lo que hoy llamaríamos una "historia novelada" o acaso una "novela histórica"? La pregunta queda sin respuesta y la cuestión se vuelve bizantina: como discutir la naturaleza de la luz que iluminó el Tabor, ya que no hay comprobación posible, pues el manuscrito del Padre Ochoa parece irremisiblemente perdido; guardamos su título como una probabilidad de que haya sido una novela (que sería la tercera o cuarta, cronológicamente, de las escritas en Nueva España, según mis noticias) y quede la reso-

9 MOORE, op, cit., loc. cit.

10 José Mariano de Beristán y Souza: Biblioteca Hispano Americana Septen. trional. 30 edición. Eds. Fuente Cultural, Librería Navarto, México. 1947. 
lución final para el dia en que aparezcan y puedan ser examinadas aquellas 142 hojas y entonces dará el fallo el crítico que tenga la fortuna de verlas.

Transcurren dos tercios del siglo xvil sin que aparezca otra obra que pueda figurar en el apartado de la novela. Sólo hasta 1690 surge un pequeño libro de un gran autor del que ahora, en la época moderna, varios dirán que fue uno de los pocos ejemplos de la novela de Nueva España. El autor es don Carlos de Sigüenza y Góngora y al libro, recortando los circunloquios de su portada, se le conoce modernamente con el título de Los Infortunios de Alonso Ramirez. Las opiniones acerca de su carácter novelesco son variadas, desde los que lo afirman sin vacilar hasta los que lo niegan rotundamente, pasando por diversos matices, de los cuales, dado el carácter del presente estudio, no parece impertinente citar algunos de los más relevantes ejemplos:

En un breve estudio fechado en 1925, Francisco Monterde (que por entonces casi iniciaba su hoy copiosa obra de estudios literarios), menciona Los Sirgueros de la Virgen, La portentosa Vida de la Muerte (a la que más tarde me referiré), El Peregrino con Guia del Dr. D. Marcos Reynel Hernández y Los Infortunios de Alonso Ramirez, calificando a todos ellos de "libros en que podemos descubrir el germen de la novela mexicana que no llegó a ser escrita en la época colonial...". ${ }^{11}$

Julio Jiménez Rueda encontraba que "cierto carácter novelesco tienen Los Infortunios de Alonso Ramirez...". 12 Mientras que, en un manual análogo al citado, Carlos González Peña afirma lo contrario: "Sigüenza y Góngora lanza en 1690 Los Infortunios de Alonso Ramirez, relato histórico que por su cariz romancesco podría parecer novela pero que de hecho no lo es...". 13

Un docto estudioso de las letras y sucesos de nuestra época virreinal, y muy especialmente de Sigüenza y Góngora, el investigador Irving A. L.eonard, desde hace más de seis lustros veía en don Carlos más bien a

11 Francisco Monterde Garcia Icazbalceta: "Introducción" en Bibliografia de Novelistas Mexicanos, por Juan B. Iguiniz. Monografias Bibliográficas Mexicanas, No 3, México, 1926.

12 Julo Juménez Rueda: Historia de la Literatura Mexicana. 6" edición, Eds. Botas, México, 1957, p. 132.

13 Carlos Gonzílez PeNa: Historia de la literatura Mexicana. 4" edición. Editorial Porrúa, S. A., México, 1949, p. 200. 
un precursor de la novela: "... one of the most readable products of the facile pen of Don Carlos, The Misfortunes of Alonso Ramirez... a distinctive piece of writing which, as a narrative of adventure, may possibly be regarded as the forerunner of the Mexican novel...". ${ }^{14} \mathrm{Y}$ recientemente ha reiterado aquel juicio de hace treinta años, aunque dejando la responsabilidad a otros críticos: "The most charming of these journalistic narratives is a curious account of the misadventures of a Puerto Rican youth during a journey around the world entitled The Misfortunes of Alonso Ramirez. Told in the first person, it purports to relate the story of his capture by English pirates who later set him adrift in a small boat wich was finally wrecked on the Yucatan coast where he had a Robinson Crusoe-like adventure. Though Sigüenza slows the pace of his recital with pedantic details, he is writing in the picaresque tradition of Spanish literature and with more than his accustomed verve. Indeed, some literary historians like to classify this curious relación as a precursor of the Mexican novel." 15

Idéntico juicio aparece firmado por otro ilustre erudito y fecundo escritor, el Marqués de San Francisco, quien dice: "La curiosa relación que escribió don Carlos de los infortunios padecidos por Alonso Ramírez (que algunos consideran precursora de la novela mexicana) apareció en $1690 . . . " ; 16$ pero cabe observar que esa obra de Sigüenza está recopilada, por el citado Marqués, en un volumen que lleva el título de Relaciones históricas, por lo que parece que dicho relato está alli mismo considerado como perteneciente más al género histórico que al novelesco.

Esa imprecisión de la clase a que el libro pertenece la apunta clara. mente Alfonso Reyes en un par de líneas: "Sus [de Sigüenza] Infortunios de Alonso Ramírez, un natural de Puerto Rico, son una biografía, apenas novelada a lo sumo, de aquella existencia real y tormentosa...". ${ }^{17}$

Difieren, pues, considerablemente las opiniones; probablemente lo más indicado es examinar de cerca lo que tales páginas contienen y de ese examen sacar la conclusión que proceda.

14 Irving A. Leonard: Don Carlos de Sigüenza y Góngora. A Mexican Savant of the Seventeenth Century. University of California Press, Berkeley, Cal., 1929, p. 29.

15 Irving A. Leonard: Baroque Times in Old Mexico. The University of Michigan Press, Ann Arbor, 1959, p. 203.

16 Manuel Romero de Terreros: "Prólogo" en Carlos de Sigüenza y Góngora. Relaciones Historicas. Biblioteca del Estudiante Universitario, vol. 13. Ediciones de la UNAM, México, 1940.

17 Alfonso Reyfs: Op. cit., p. 92. 
Comienza el capítulo I presentando al personaje principal, Alonso Ramírez, su origen, familia y algunos datos de Puerto Rico, su tierra natal; todo muy resumido, así como el viaje de aquella isla a San Juan de Ulúa, de donde pasa a Puebla y luego a México, ocasión que aprovecha la pluma de Sigüenza para engalanar con barroquismos sus elogios: "Lástima es grande el que no corran por el mundo grabadas a punta de diamante en láminas de oro las grandezas magnificas de tan soberbia ciudad...".18 Siguen breves referencias a Oaxaca y al Soconusco, por donde anduvo buscando fortuna el héroe del relato $\mathrm{y}$, por fin, cuenta su partida de Acapulco rumbo a Filipinas, el año de 1682.

El capítulo il relata el recorrido de ese viaje, con tal abundancia de datos geográficos y de navegación, tan cuidados y precisos, que sin duda proceden íntegramente de Sigüenza y no del relato de Ramírez, pues éste no podía tener más conocimientos de marinería que las muy superficiales observaciones que hubiera podido haber hecho en su único viaje precedente, de San Juan a La Habana y a Veracruz, ya que su propio oficio era el de carpintero y no aprendió cosas de mar hasta que estuvo en Filipinas, como él mismo lo dice. Siguen, en el mismo capítulo, referencias a islas y lugares que conoció; esas noticias de Macao o Macán, de Batavia, de Malaca, etc., sí deben proceder exclusivamente de Alonso Ramírez: allf ya no hay datos geográficos sino puro relato, en veces pintoresco, con la sola excepción de un detalle extremadamente preciso, porque así debía conservarlo en la memoria aquel infeliz y lo recordaría con horror para siempre, el momento en que cayó prisionero de los piratas ingleses, que señala con toda exactitud: "Eran entonces las seis de la tarde del día martes cuatro de marzo de mil seiscientos ochenta.y siete."

El capítulo III, una docena de cuartillas aproximadamente, es el núcleo de los Infortunios. Allí están los relatos de los robos, muertes, saqueos, torturas, que los piratas cometían en las costas y lugarejos que tocaban o en las naves que asaltaron, en aquel larguísimo derrotero iniciado en Filipinas que continuaron por las Islas de la Sonda, luego por el Océano fndico, bordearon Africa desde la altura de Madagascar y volteando el Cabo de Buena Esperanza recorrieron gran parte de la costa occidental, luego rumbo al Poniente cruzaron el Atlántico y llegaron a la

18 Carlos de Sigüenza y Góncora. Obras Históricas. Edición y prólogo de Joué Rojas Garcidueñas. Colec. Escritores Mexicanos, vol. 2 (2" ed.) Editorial Porría, S. A., México, 1960, p. 12. 
costa de Brasil, en la desembocadura del Amazonas, es decir casi en la línea del Ecuador.

No se declara el tiempo transcurrido en tan largo recorrido, pero sacando cuentas aproximadas parece que terminaría en junio o julio de 1689; de modo que la navegación del narrador, prisionero de los piratas ingleses, debe de haber durado algo más de dos años, más concretamente 27 o 28 meses.

Todo lo que en esa parte del libro se cuenta fue, sin duda, relatado integramente por Alonso Ramirez; esa parte es, como dije, la principal de los Infortunios y lo que más interesaría a Sigüenza y le gustaría publicar, pues alli se trata de los mares y de las islas que hoy son de Indonesia, de la India, de las costas de Africa, etc., regiones y grandes partes del mundo de las que casi nada se sabía en México, porque desde mucho tiempo atrás estaban aquellos lugares en poder de holandeses, de portugueses, de ingleses y eran, por lo mismo, inaccesibles a los españoles. Por ello Sigüenza no podía enriquecer o retocar esa parte del relato con detalles geográficos de grados y latitudes, como sí lo hizo en el Capítulo II, para la ruta de Filipinas, de la que sin duda él sabía mucho, ya por los mapas y escritos ya por lo que de viva voz contaban los capitanes y pilotos que venían en la "nao de la China", con quienes trataba el curioso cosmógrafo cada vez que le era posible hacerlo.

Pero, también, ese capitulo central demuestra que al redactar las páginas de su libro, Sigüenza no tuvo ni un ápice de intención de novelar ni fantasear (ni era ello propio de su idiosincrasia). Dije que ese capitulo wil es corto, a pesar de que se refiere a un recorrido marítimo largo con prolongadas estancias en islas y costas, que todo duraría como dos años y alcanzó a tres cuartas partes de la redondez de la tierra; entonces, ¿qué mejor ocasión podfa ofrecerse para novelar cuanto quisiera, de haber sido tal su propósito? Por otra parte, si recordamos los antecedentes literarios de su tiempo, los cuales conocía bien Sigüenza, gran letrado, entre los que estaban (como dije en las primeras de estas páginas) la novela bizantina o de aventuras, es de presumir que si don Carlos hubiese tenido intención, siquiera mínima, de novelar, todo ese capítulo in habria crecido desmesuradamente, llenándose de las más grandes y portentosas aventuras y de las más extrañas descripciones de aquellos lugares, todo lo cual habria atraido la atención y gustado muchísimo más al público que el relato, demasiado escueto y simple, del pobre marinero náufrago que lo cuenta, pero absolutamente impropio del sabio erudito barroco que lo transcribe y que debe de haber hecho no pocos esfuerzos 
para que los adjetivos, observaciones, consideraciones y comentarios, no pasaran de su mente a los puntos de la pluma; todo lo cual es, para mí, una de las mejores pruebas de la deliberada voluntad de Sigüenza de no incurrir en el terreno de la ficción, es decir de la novela, conservándose en el puro relato objetivo, en el campo árido pero claro de lo que podfa servir al conocimiento cientifico de la geograffa, hasta donde le era posible con los medios y las circunstancias de su momento. Tanto es así que, en cambio de esa extraña carencia de ficción, donde tan fácil era ponerla, la única intervención de Sigüenza se percibe en algunos toques precisos de erudición (en ese tiempo lo era), de los que es claro ejemplo el último párrafo del capítulo ni cuando dice:

"En el tiempo de dos semanas en que fuimos al luengo de la costa y sus vueltas disminuyendo altura, en dos ocasiones echaron seis hombres a tierra en una canoa, y habiendo hablado con no sé qué portugueses y comprádoles algún refresco, se pasó adelante hasta llegar finalmente a un río dilatadísimo sobre cuya boca surgieron en cinco brazas, y presumo fue el de las Amazonas, si no me engaño." 10

En esta parte final, lo del "río dilatadisimo" me parece versión directa de Alonso Ramírez, pero don Carlos no pudo contenerse de mejorar el dato con el nombre propio del río y lo pone, aunque entre dos velos que cautelosamente precaven del error posible; " $y$ presumo, fue el (rio) de las Amazonas, si no me engaño"; que eso proviene de Sigüenza parece indudable pues écómo podría saber ese nombre Alonso Ramirez?, los piratas no se lo dijeron y él acaso nunca habría ni ofdo mencionar tal río.

Lógicamente o, mejor dicho, cronológicamente, el capítulo iv debería contener la segunda parte de la gran aventura marítima de Alonso Ramírez: la que pasó con sus siete compañeros de cautiverio desde el momento en que los piratas les dieron libertad y una mala fragata, en la boca del Amazonas, hasta que llegaron a Yucatán, pero en realidad no es ese el contenido de dicho capítulo Iv, sino los tormentos y penalidades que sufrieron los cautivos de los piratas durante el largo viaje relatado en el capítulo precedente, así como un intento de rebelión y otros sucesos, cosas todas del mayor interés para Alonso Ramirez que las padeció, pero que Siguienza pospone y separa de la navegación en que esos hechos ocurrieron; sin duda en el primer relato, en el que hizo Alonso

19 Op. cit., p. 36. El subrayado es mio. 
Ramírez directamente y en forma oral, primero al Virrey y luego a Sigüenza, todo ello andaría mezclado según fue sucediendo, pero a don Carlos eso le parecería -y con razón- confuso y en su versión separó, sin romper el relato, la parte relativa al largo viaje, propiamente tal, con las referencias objetivas necesarias: lugares, mares, rumbos, indígenas de las islas, etc., todo lo cual a él le interesaba muchísimo como geógrafo, y todo eso lo apartó, aunque sin desligarlo, de los sucesos de importancia subjetiva o personal para Alonso Ramírez (como que sufrió los malos tratos y crueles tormentos en carne propia), pero que Sigüenza vería como cosa secundaria o al menos subsidiaria del relato del viaje, que era para él lo principal, como he dicho, por lo que tenía de información o enseñanza. Por lo demás, esa separación y el deseo de evitar confusiones están proclamando que don Carlos no deseaba en ese escrito hacer literatura (en el mejor y más riguroso sentido, es decir hacer una obra que procure emocionar o conmover, pues él, con su formación clásica, sabía bien que esa es la función de la literatura, como la de cualquiera de las bellas artes), sino que deseaba escribir, y lo hizo, una obra destinada a enseñar, a divulgar conocimientos, propósito didáctico acaso no del todo consciente pero que, a mi juicio, era la fuerza más honda que lo movía, entonces, a recoger, redactar y publicar los relatos que forman ese pequeño libro.

El capítulo v se refire a la navegación que hicieron Alonso Ramírez y siete compañeros de infortunio ya libres, desde la costa de Brasil hasta el naufragio en un cayo o isla frente a lo que hoy es Quintana Roo o acaso Belice, es decir, algún lugar en el sur de la costa oriental de la península de Yucatán. Sigüenza, respetuoso de la narración, no la altera, solamente añade en paréntesis o notas los nombres de las Antillas que corresponden a las islas que vio o tocó Ramírez pero de las cuales, salvo la de Guadalupe, éste desconocía los nombres como expresamente lo dice en una explicación y honradísima confesión de su ignorancia:

"No se espante quien esto leyere, de la ignorancia en que estábamos de aquellas islas porque habiendo salido de mi patria de tan poca edad, nunca supe (ni cuidé de ello después), qué islas son circunvecinas y cuáles sus nombres; menos razón había para que Juan de Casas, siendo natural de la Puebla, en lo mediterráneo de la Nueva España, supiese de ellas, y con más razón militaba lo propio en los compañeros restantes, siendo todos originarios de la India 
oriental donde no tienen necesidad de noticia que les importe de aquellos mares; pero no obstante bien presumia yo el que era parte de la América en la que nos hallábamos..." so

El viaje termina (al fin de ese capítulo), con la fragata encallada, golpeada por el mar y los pocos sobrevivientes, náufragos, pisando tierra en costas de Yucatán, hacia mediados, posiblemente, de octubre de 1689.

Viene, luego, el capítulo vi que refiere las tribulaciones pasadas en la desierta costa (murieron dos de los compañeros hindúes), hasta encontrar a unos indios mayas que entendian el castellano y luego a su amo, un español que andaba en cacería de indios para apresarlos y venderlos, so pretexto de catequizarlos.

El capítulo final, que es el vir, cuenta la llegada a Mérida y las declaraciones oficiales; nadie auxilia a los náufragos, antes los despojan de su fragata varada y de sus poquísimos bienes, hasta que por último las autoridades envian a Ramírez a México, adonde llegó el 4 de mayo de 1690, completando así su periplo. Se cuenta cómo fué a saludar al Virrey Conde de Galve (lo cual de no ser rigurosamente cierto ni lo hubiera escrito Sigüenza ni se habrfa publicado) quien lo envió a don Carlos de Sigüenza el que oyó los relatos de Alonso Ramírez y los apuntó, para luego redactarlos y publicarlos como lo hizo, además de prestar valiosas ayudas al infeliz náufrago hasta lograr colocarlo en la Armada de Barlovento, con lo cual da fin el libro.

Creo que con ese amplio resumen y las consideraciones apuntadas, es más que suficiente para concluir que la obra de Sigüenza, Infortunios de Alonso Ramirez ${ }^{21}$ no es obra de ficción, no es novela, es obra que pertenece al género, hoy tan difundido, de los relatos de viajes y fue escrito por Sigüenza con el doble ánimo de registrar sucesos muy raros y divulgar conocimientos, entonces muy escasos, de lugares y pueblos remotos, de los que sólo muy de tarde en tarde llegaban a México noti-

20 Op. cit., p. 50.

21 En esa forma es como suele citarse el libro en cuestión, abreviando (como en otros muchos casos similares) su largo y barroco titulo original, pues la portada de la 1" edición reza asi: "Infortunios que Alonso Ramirez natural de la ciudad de San Juan de Puerto Rico padecio, asi en poder de ingleses piratas que lo apresaron en las Islas Filipinas, como navegando por si solo y sin derrota hasta parar en la costa de Yucatdn, consiguiendo por este medio dar vuelta al mundo. Describelos D. Carlos de Sigüenza y Góngora, Cosmógrafo y Catedrático de Matemáticas del Rey Nuestro Señor en la Academia Mexicana. Con licencia, en México, por los Herederos de la Viuda de Bernardo Calderón, en la calle de San Agustín. Año de 1690." 
cias confusas y contradictorias. Don Carlos de Sigüenza se habria sorprendido muchísimo y probablemente se habria indignado no poco -dado su temperamento irascible y su padecimiento biliar ya muy avanzado-, si se hubiera enterado que algún comentador de su libro se atrevería a calificarlo o clasificarlo camo novela.

Por último, en lo que respecta al libro de Sigüenza y Góngora, cabe citar dos referencias más, en cuanto a la realidad histórica del personaje y del asunto de esa obra. En la dedicatoria al Conde de Galve, dice el autor: "Cerró Alonso Ramírez en México el circulo de trabajos, con que... dio vuelta al mundo, y condoliéndose Vuestra Excelencia de él cuando los refería... etc.", y sin duda no habria asegurado don Carlos una acción del Virrey si eso no fuese verdad. $Y$ en seguida, en la aprobación dada por el P. Ayerra de Santa María, el 26 de junio de 1690, comienza diciendo: "Así por obedecer ciegamente el decreto de V.S. en que me manda censurar la relación de los Infortunios de Alonso Ramirez, mi compatriota, descrita por D. Carlos de Sigüenza y Góngora ... etc.", confirmando en tal forma el lugar natal del héroe del relato ya que sabamos, con seguridad, que el Pbro. don Francisco Ayerra y Santa María fue portorriqueño de origen.

En el siglo xvin la moda literaria no fue, en general, propicia a la novela; pero de ningún modo quiere eso decir que yo atribuya a las tendencias literarias europeas la responsabilidad de que en la Nueva España dicho género no fuera cultivado, o mejor dicho lo fuese muy poco, pues todavía podemos encontrar alguna otra referencia de otro manuscrito inédito.

Beristáin y Souza menciona a José Sancha; dice: "SANcha (D. José) presbitero mexicano, alumno de la Ven. congregación de S. Pedro y mayordomo administrador del hospital de sacerdotes de la misma. Escribió: Fabiano y Aurelia. Novela moral dedicada al Dr. y Mtro. D. Gregorio Pérez Cancio, Cura de la Parroquia de la Soledad de México. MS. original en la librería del Colegio de S. Pedro." 22 Don Francisco Pimentel conoció tal manuscrito y de él refiere que estaba fechado, en esta ciudad, "a 20 de septiembre de 1760, y que perteneció al bibliófilo mexicano Andrade. . " Como ese es el único testimonio que poseemos, vale la pena transcribir toda la página que le dedica el señor Pimentel, que dice:

22 Beristíin: $O p_{\uparrow}$ cit. 
"Esa novela carece de mérito. Comienza por una dedicatoria al Dr. Pérez Cancio; sigue la introducción, pequeño cuento sin atractivo alguno, de amores poco decentes; viene después la novela cuyo argumento es una empalagosa relación de amoríos livianos, sin gracia, sin interés y sin importancia alguna, bajo la forma de un lenguaje rebuscado, altisonante, obscuro y pedantesco.

"Sírvanos de muestra el siguiente retrato de la protagonista: . Tenia el cuerpo de competente estatura, y tan blanca la color que atendiendo a las propiedades y reflejando en la esencia, podía duclarse alabastro vestido, o pedazo de nieve con alma. Sus cabellos dorados, con lazos, en que desde luego hubiera quedado preso el poderoso Neptuno si no hubiera visto primero los de la cruel Meduza [sic]. Sus ojos eran modestamente alegres más vivos que los ciento de Argos, porque éstos con ningún engaño pudieron descuidarse y aquéllos con la flauta de Mercurio llegaron a dormirse. Las mejillas vistoso enjambre de colores, y de éstas agraciada y suspensa contienda, porque aunque se alterase encendida, la otra se detenía desmayada. La boca dividido clavel o boca concha que abrigaba en su rosado seno iguales y menudas perlas. Los brazos bulliciosos cristales, en cuya transparente armonía se dejaban ver las delicadas venas; y como éstas se situaban estiradas se engañaba la vista pensando que eran escamas... nutridas en los suspensos acuos. Las manos escápulos de nieve, torneadas a sonrojo del arte, dignas por esto de aquella generosa alabanza conque el poeta griego encareció la perfección de la Aurora. Ceñia la admiración su cintura y fatigaba la brevedad de su pie. Toda era un asombro y la hacía más peregrina su genio o su ingenio, pareciéndose en lo primero a la dócil Diana hija de su hermano, y en lo segundo a la divina Palas, nacida de la cabeza de Júpiter. Parecia, en fin, que excediendo a aquella diosa que produjo al poderoso Vulcano, había obligado más que ésta a los dioses para que la adornaran con tan divinos dones.

“... basta lo dicho para comprender que la obra de Sánchez [Pimentel llama José González Sánchez al que Beristáin denomina José Sancha] no merece el título de novela moral que le da equivocadamente Beristáin en su Biblioteca; el autor mismo, en la portada, la califica simplemente de novela entretenida; pero ni aun eso tiene." 23

23 Pimentel: Op. cit. pp. 276 y 277. 
Por muchos motivos, que sería excesivo explicar aqui, tengo a Pimentel por crítico muy parcial, limitado y discutible, pero a juzgar por esas veinticinco o treinta líneas que cita $-y$ que he transcrito-, parece que esta vez tenia razón en sus duros calificativos sobre Fabiano y Aurelia, y probablemente no es de lamentar que se haya perdido el manuscrito en cuestión.

Dos obras más, en las postrimerias del virreinato, han sido a veces mencionadas o clasificadas como novelas, son: La portentosa vida de la mucrte de fray Joaquín Bolaños y La levadura del sueño de sueños de José Mariano Acosta Enríquez. ${ }^{94}$ Ninguna de ellas es novela, ambas son ensayos aunque de indole muy distinta $y$, por lo mismo, ajenas al propósito de estas páginas.

Apenas muy poco después de que Acosta Enríquez escribiera su Sueño de sueños, todo lo que constituyó la época virreinal entra en crisis: la autoridad suprema del Rey se eclipsa por la interposición de las armas napoleónicas; faltas de su apoyo legal, las instituciones sufren grave desequilibiro; todas las formas de la vida política oscilan y son discutidas; poderosas fuerzas sociales, hasta entonces latentes, exsurgen con violencia; naturalmente, el sismo social repercute y se manifiesta en las expresiones de la cultura. Así se produce una década, o poco más, de transición entre dos etapas de nuestra historia y en ese momento nace lo que, en rigor, debe considerarse como la primera novela propiamente mexicana, de la pluma de José Joaquín Fernández de Lizardi. Pero nada de aquello: crisis, agitaciones, subversión de valores establecidos, eclosión de formas nuevas, corresponde a lo que históricamente debemos entender por la Nueva España.

24 Jonquin Bolaños: La portentosa vida de la Muerte. Prólogo y selección de Agustin Yánez. Biblioteca del Estudiante Universitario, vol. 45. Eds. de la UNAM, México, 1944.

Jost Mariano Acosta Enríquez: Sueño de Sueños. Prólogo y selección de Julio Jiménez Rueda. Bibiloteca del Estudiante Universitario, vol. 55, Eds. de la UNAM, México, 1945.

La obra de Acosta Enríquez es una de las últimas producciones literarias que pertenecen, propiamente, a nuestra época del virreinato; la fecha de su composición es la de 1801, esclarecida en el importante estudio de J. M. GonzÁlez de Mendoza: "La fecha del Sueño de Sueños", en El Universal, México, 22 de octubre de 1958. 
Por lo tanto, la muy escasa novelística de Nueva España, con las condiciones y circunstancias que en estas páginas he pretendido señalar, queda encerrada entre la novela pastoril de Bernardo de Balbuena, de los finales del siglo xvi, hasta la perdida novela de Sancha, de 1760; a reserva de que algún hallazgo posterior modifique, tal vez, estas aserciones que, como todo lo que a investigaciones históricas se refiere, no deben ser consideradas sino en función de nuestros conocimientos hasta hoy. 